\title{
Potencial Alelopático De Myrcia guianensis ${ }^{1}$
}

\author{
Allelophatic Potential of Myrcia guianensis
}

\author{
SOUZA FILHO, A.P.S. ${ }^{2}$, SANTOS, R.A. ${ }^{3}$, SANTOS, L.S. ${ }^{3}$, GUILHON, G.M.P. ${ }^{3}$, SANTOS, A.S. ${ }^{3}$, \\ ARRUDA, M.S.P. ${ }^{3}$, MULLER, A.H. ${ }^{3}$ e ARRUDA, A.C. ${ }^{3}$
}

\begin{abstract}
RESUMO - O uso do fogo e de roçadeira para controle de plantas daninhas em pastagens tem se mostrado pouco efetivo. Já o uso de herbicidas sintéticos, embora mais eficaz no controle de plantas daninhas, tem sido questionado quanto ao impacto ambiental. Portanto, a busca de compostos naturais para possível utilização como herbicida é de fundamental importância. Esses fatos motivaram o presente estudo, que teve como objetivos isolar, identificar e caracterizar a atividade alelopática potencial de substâncias químicas produzidas por Myrcia guianensis (pedra-ume-caá). Foram analisados os efeitos potenciais alelopáticos de extratos brutos, partições, óleo essencial e das substâncias químicas isoladas (ácido gálico e ácido protocatecuico) sobre a germinação e o desenvolvimento da radícula e do hipocótilo das plantas daninhas Mimosa pudica (malícia) e Senna obtusifolia (mata-pasto) em pastagens. Os extratos brutos e as partições foram analisados em concentração de 1\%; o óleo essencial, em concentrações de 1, 5, 10, 15 e 20 ppm; e as substâncias isoladas, em concentrações de 15, 30, 45 e 60 ppm. A espécie malícia se mostrou mais sensivel aos efeitos alelopáticos dos extratos brutos e das partições. O óleo essencial inibiu a germinação da malícia e estimulou a germinação no mata-pasto. A atividade alelopática das substâncias químicas isoladas esteve associada à concentração, e a atividade mais intensa foi em 60 ppm.
\end{abstract}

Palavras-chave: alelopatia, pedra-ume-caá, ácido gálico, ácido protocatecuico.

\begin{abstract}
The use of fire and mowing as weed methods have proved inefficient. Although more efficient, synthetic chemical herbicides are usually related to environmental problems. Thus, the search for natural herbicides has become a priority matter. Based on these facts, research was conducted on Myrcia guianensis (pedra-ume-caá) including the isolation and identification of chemical substances with allelophatic activity. The allelophatic effects of extracts, fractions, essential oils, and isolated chemical substances (gallic acid and protocatechuic acid) on germination and radicle and hypocotyl growth of weed species Mimosa pudica (malicia) and Senna obtusifolia (mata-pasto) were analyzed. Extracts and fractions were analyzed at a concentration of 1\%, essential oils at 15,30,45, 60 ppm and the isolated chemical substances at 15, 30, 45, $60 \mathrm{ppm}$. Malicia showed more sensitivity to the allelophatic effects of extracts and fractions. The essential oil inhibited the germination of $\boldsymbol{M}$. pudica but stimulated that of S. obtusifolia. The allelophatic effects of the chemical substances were concentration dependent and the strongest activity was observed at $60 \mathrm{ppm}$.
\end{abstract}

Key words: allelopathy, pedra-ume-caá; gallic acid; protocatechuic acid.

\section{INTRODUÇÃO}

O controle de plantas daninhas em áreas de pastagens cultivadas tem sido realizado pelo uso do fogo e da roçadeira e, mais recentemente, empregando herbicidas sintéticos. O uso do fogo e de roçadeira, isoladamente ou em conjunto, tem se mostrado pouco eficiente no controle de plantas daninhas em médio e longo prazo, levando os

\footnotetext{
Recebido para publicação em 17.5.2006 e na forma revisada em 10.11.2006.

Embrapa Amazônia Oriental, Trav. Dr. Enéas Pinheiro, S/N. 66095-100, Belém-Pará, <apedro@cpatu.embrapa.br>. ${ }^{3}$ Universidade Federal do Pará, Av. Augusto Corrêa, 1, 66075-900 Belém-PA.
} 
produtores a repeti-los sistematicamente, o que eleva o custo de manutenção das culturas. Já o uso de herbicidas sintéticos, embora seja considerado um método de controle eficaz para um número considerável de espécies de plantas daninhas, tem sido questionado quanto ao seu impacto ambiental. Portanto, a busca de herbicidas naturais que não apresentem os inconvenientes dos herbicidas sintéticos é de fundamental importância, visando minimizar o impacto ambiental causado por essas atividades.

Nesse contexto, a investigação de propriedades alelopáticas em plantas pode representar uma oportunidade para equacionar esses problemas (Souza Filho et al., 2005). Com esse objetivo, vários trabalhos foram desenvolvidos nos últimos anos para estudar diversas espécies vegetais com potencial alelopático (Borges et al., 1993; Lisanework \& Michelsen, 1993; Gonzáles et al., 1995; Rizvi et al., 1999; Souza Filho \& Alves, 2000).

Estudos recentes em um grupo de espécies do gênero Myrcia DC. (Myrtaceae), conhecidas vulgarmente como "pedra-ume-caá", dentre as quais podem-se destacar Myrcia uniflora, Myrcia multiflora, Myrcia guianensis, Myrcia salicifolia, Myrcia speciosa e Myrcia sphaerocarpa, revelaram a existência de propriedades biológicas de várias substâncias isoladas e também nos extratos brutos e infusões (Yoshikawa et al., 1998; Matsuda et al., 2001; Matsuda et al., 2002; Yoshikawa et al., 2002; Guaré Cruz et al., 2004; Limberger et al., 2004).

Este trabalho teve como objetivos isolar, identificar substâncias químicas produzidas por Myrcia guianensis e caracterizar a atividade alelopática potencial sobre a germinação das sementes e o desenvolvimento da radícula e do hipocótilo de duas espécies de plantas daninhas.

\section{MATERIAL E MÉTODOS}

\section{Coleta e preparo do material botânico}

A coleta foi realizada em área próxima à cidade de Santarém-PA, e a identificação efetuada por botânicos da Embrapa - Amazônia Oriental, localizada em Belém-PA. Em seguida, o material botânico (folhas) foi seco em temperatura ambiente e, posteriormente, triturado em moinho de facas.

\section{Obtenção do óleo essencial}

O óleo essencial foi obtido a partir de $1,5 \mathrm{~kg}$ de folhas frescas de Myrcia guianensis, utilizando o método de hidrodestilação em extrator contínuo do tipo Clevenger modificado. Foi obtido 1,611 g de óleo, com rendimento de $0,11 \%$.

\section{Procedimentos de isolamento e identificação das substâncias quimicas}

A partir de 5,80 kg do material seco e triturado, foram realizadas extrações a frio com os solventes orgânicos na seqüência de polaridade crescente: hexano, acetato de etila, metanol e solução hidroalcoólica (etanol e água 8:2). Cada solução foi filtrada e em seguida concentrada sob pressão reduzida, fornecendo os extratos brutos: hexânico (EBH), acetato de etila (EBAE) e metanólico (EBM) (Figura 1). Esses extratos passaram por método de partição seqüencial (extração líquido-líquido) com os solventes: hexano, diclorometano e acetato de etila, obedecendo à ordem crescente de polaridade. Cada extrato forneceu as partições: hexânica (PH), diclorometânica (PDM) e acetato de etila (PAE) (Figura 1).

As partições obtidas passaram pelo método de fracionamento cromatográfico, objetivando o isolamento e a purificação das substâncias químicas, envolvendo as seguintes técnicas: Cromatografia de Coluna por Via Úmida (CCVU), utilizando sílica-gel como fase estacionária e mistura de solventes como fase móvel; Cromatografia de Camada Delgada Comparativa (CCDC); e Cromatografia de Camada Delgada Preparativa (CCDP).

As substâncias químicas foram identificadas através da análise dos espectros de Ressonância Magnética Nuclear uni e bidimensional (RMN ${ }^{1} \mathrm{H}$ e RMN ${ }^{13} \mathrm{C}$ ), DEPT e COSY.

\section{Procedimentos dos bioensaios para o estudo do potencial alelopático}

Avaliou-se a atividade alelopática de duas espécies bioindicadoras que são plantas daninhas de áreas de pastagens, comuns na região amazônica: Mimosa pudica (malícia) e 
Senna obtusifolia (mata-pasto). Foram analisados os efeitos alelopáticos sobre diferentes parâmetros: percentual de germinação das sementes e desenvolvimento da radícula e do hipocótilo.

A germinação das sementes foi realizada em câmara de germinação à temperatura de $25{ }^{\circ} \mathrm{C}$ e fotoperíodo de 12 horas, com acompanhamento de quatro dias, para verificação do aparecimento da radícula (germinação fisiológica). A cada dia foram contadas e eliminadas as sementes germinadas. Foram utilizadas 10 sementes de cada espécie, adicionadas em placas de Petri (uma espécie em cada placa).

Os bioensaios para o estudo do potencial alelopático no desenvolvimento da radícula e do hipocótilo foram realizados em condições de $25{ }^{\circ} \mathrm{C}$ de temperatura e fotoperíodo de 24 horas. Ao final de um período de 10 dias de crescimento, mediu-se o comprimento da radícula e do hipocótilo para determinar a variação de desenvolvimento. Foram usadas duas sementes pré-germinadas, com três dias de germinação, adicionadas em placas de Petri (uma espécie em cada placa).

Os extratos brutos e as partições foram avaliados em soluções na concentração de 1\% (m/v), utilizando como veículo de dispersão acetato de etila e metanol. Para o óleo essencial, as concentrações foram: 1 ppm, na germinação das sementes, e 5, 10, 15 e 20 ppm no desenvolvimento da radícula e do hipocótilo, utilizando como solvente éter etílico. A avaliação das substâncias químicas isoladas foi realizada em soluções de 15, 30, 45 e 60 ppm, utilizando como dispersante metanol.

Foram adicionados em cada placa de Petri $3 \mathrm{~mL}$ de solução dos extratos brutos, das partições, do óleo essencial ou das substâncias isoladas. Após a evaporação do solvente, adicionou-se água destilada e, durante o período, foi adicionado água destilada sempre que necessário.

\section{Análise estatística}

O delineamento experimental para todos os bioensaios foi inteiramente casualizado, com três repetições, em modelos hierárquicos com dois fatores. Para efeito de comparação da atividade potencial alelopática, utilizou-se água destilada como testemunha. Os dados foram submetidos à análise de variância pelo teste $\mathrm{F}$ e as médias comparadas pelo teste de Tukey (5\%). Utilizou-se o sistema SAS para análise de dados (Sas, 1989).

\section{RESULTADOS E DISCUSSÃO}

\section{Isolamento e identificação das substâncias químicas}

Os procedimentos que levaram ao isolamento das substâncias químicas testadas estão apresentados na Figura 1. Nas partições obtidas, houve a avaliação dos efeitos alelopáticos. Como a partição acetato de etila foi uma das que apresentaram maior atividade, foi submetida a fracionamentos cromatográficos.

Através de CCVU (Cromatografia de Coluna por Via Úmida) filtrante, utilizando os sistemas de solventes hexano, hexano/acetato de etila 50\%, acetato de etila, acetato de etila/ metanol 50\% e metanol, foram obtidas cinco frações (Figura 1). As frações hexano/acetato

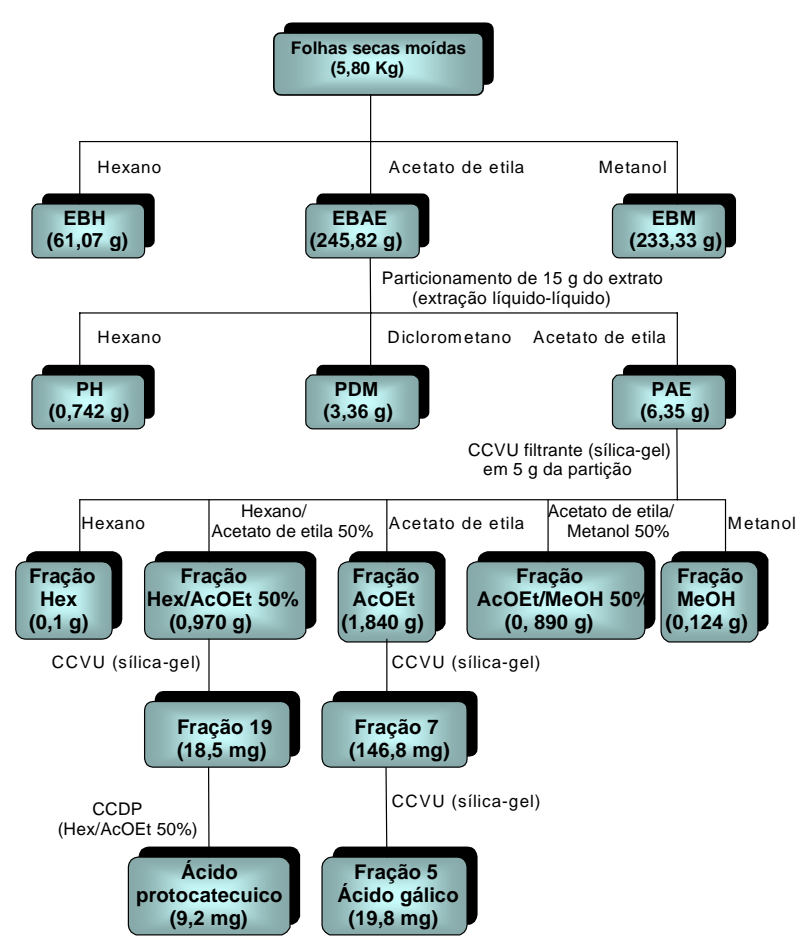

Figura 1 - Procedimentos para isolamento dos ácidos protocatecuico e gálico. 
de etila 50\% e acetato de etila 100\% foram submetidas a outra CCVU, utilizando os solventes hexano/acetato de etila com polaridade crescente. $\mathrm{O}$ fracionamento da primeira fração forneceu a fração 19, que passou por CCDP (Cromatografia de Camada Delgada Preparativa), utilizando como eluente hexano/acetato de etila 50\%, fornecendo o ácido protocatecuico. O fracionamento da fração acetato de etila forneceu a fração 7, que passou por CCVU, utilizando sistemas de solventes hexano/ acetato de etila como fase móvel, isolando-se o ácido gálico.

Analisando o espectro de $\mathrm{RMN}{ }^{1} \mathrm{H}$ (Ressonância Magnética Nuclear de Hidrogênio-1) do ácido protocatecuico, observaram-se os seguintes sinais na região de hidrogênios aromáticos: um dupleto em G6,90 ( $\mathrm{J}=8,1 \mathrm{~Hz}$ ), um duplodupleto em $\mathrm{G} \nabla, 47(\mathrm{~J}=8,1$ e $1,8 \mathrm{~Hz})$ e outro dupleto em $\mathrm{G} 7,52(\mathrm{~J}-=1,8 \mathrm{~Hz})$, atribuídos, respectivamente, aos hidrogênios H-5, H-6 e H-2 (Tabela 1). No espectro de RMN ${ }^{13} \mathrm{C}$ (Ressonância Magnética Nuclear de Carbono-13) do ácido protocatecuico foram observados sinais (Tabela 1) que, em comparação com a literatura (Nunez Selles et al., 2002), caracterizaram a estrutura desse ácido (Figura 2).

O espectro de $\mathrm{RMN}{ }^{1} \mathrm{H}$ do ácido gálico mostrou apenas um intenso singleto em G7,05, que é atribuído aos dois hidrogênios equivalentes (H-2 e H-6) do anel aromático (Tabela 2). No espectro de RMN ${ }^{13} \mathrm{C}$ foram observados: um sinal em G110,3 relativo aos carbonos equivalentes C-2 e C-6; outro sinal em G146,4 referente aos outros dois carbonos equivalentes: C-3 e C-5; e um sinal em G170,4 característico de carbono carbonílico. Esses dados (Tabela 2), em comparação aos da literatura (Andersen et al., 2003), levaram à identificação da substância como sendo o ácido gálico (Figura 2).

\section{Avaliação da atividade do potencial alelopático dos extratos brutos e das partições}

Os extratos brutos acetato de etila e metanólico apresentaram maiores atividades alelopáticas nas germinações das sementes, principalmente da espécie malícia (Tabela 3). Em face do maior efeito inibitório do extrato bruto acetato de etila, optou-se pelo particionamento deste.
Tabela 1 - Dados de $\mathrm{RMN}{ }^{1} \mathrm{H}\left(\mathrm{CD}_{3} \mathrm{OD}, 300 \mathrm{MHz}\right)$ e $\mathrm{RMN}$ ${ }^{13} \mathrm{C}\left(\mathrm{CD}_{3} \mathrm{OD}, 75 \mathrm{MHz}\right)$ para o ácido protocatecuico

\begin{tabular}{|c|c|c|}
\hline Posição & ${ }^{1} \mathrm{H}(\mathrm{ppm})$ & ${ }^{13} \mathrm{C}(\mathrm{ppm})$ \\
\hline 1 & - & 129,9 \\
\hline 2 & $7,52 \mathrm{~d}(\mathrm{~J}=1,8 \mathrm{~Hz})$ & 117,8 \\
\hline 3 & - & 146,0 \\
\hline 4 & - & 151,4 \\
\hline 5 & $6,90 \mathrm{~d}(\mathrm{~J}=8,1 \mathrm{~Hz})$ & 115,7 \\
\hline 6 & $7,47 \mathrm{dd}(\mathrm{J}=8,1$ e $1,8 \mathrm{~Hz})$ & 123,7 \\
\hline 1 ' & - & 170,2 \\
\hline
\end{tabular}

Tabela 2 - Dados de $\mathrm{RMN}{ }^{1} \mathrm{H}\left(\mathrm{CD}_{3} \mathrm{OD}, 300 \mathrm{MHz}\right)$ e $\mathrm{RMN}$ ${ }^{13} \mathrm{C}\left(\mathrm{CD}_{3} \mathrm{OD}, 75 \mathrm{MHz}\right)$ para o ácido gálico

\begin{tabular}{|c|c|c|}
\hline Posição & ${ }^{1} \mathrm{H}(\mathrm{ppm})$ & ${ }^{13} \mathrm{C}(\mathrm{ppm})$ \\
\hline 1 & - & 121,9 \\
\hline 2 & $7,05 s$ & 110,3 \\
\hline 3 & - & 146,4 \\
\hline 4 & - & 139,6 \\
\hline 5 & - & 146,4 \\
\hline 6 & $7,05 s$ & 110,3 \\
\hline 1 & - & 170,4 \\
\hline
\end{tabular}

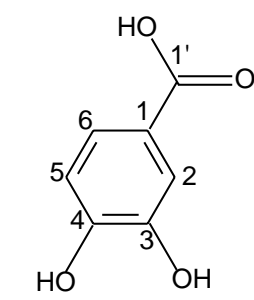

Ácido protocatecuico

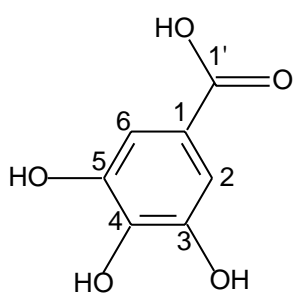

Ácido gálico
Figura 2 - Estruturas dos ácidos protocatecuico e gálico.

Tabela 3 - Efeitos potenciais alelopáticos dos extratos brutos das folhas de Myrcia guianensis sobre a germinação das sementes das plantas daninhas

\begin{tabular}{|c|c|c|}
\hline \multirow{2}{*}{ Extrato bruto } & \multicolumn{2}{|c|}{ Espécie de planta daninha } \\
\cline { 2 - 3 } & Malícia & Mata-pasto \\
\hline EBH & $29 \mathrm{Ca}$ & $5 \mathrm{Bb}$ \\
\hline EBAE & $100 \mathrm{Aa}$ & $20 \mathrm{Ab}$ \\
\hline EBM & $82 \mathrm{Ba}$ & $0 \mathrm{Cb}$ \\
\hline
\end{tabular}

Médias seguidas de letras iguais, minúsculas na linha e maiúsculas na coluna, não diferem pelo teste de Tukey (5\%).

Dados expressos em percentual de inibição em relação ao tratamento testemunha (água destilada). Soluções utilizadas na concentração de $1 \%(\mathrm{~m} / \mathrm{v})$. 
A avaliação do potencial alelopático das três partições obtidas desse extrato indicou intensas inibições nas germinações das sementes das espécies daninhas, na ordem de 100\%, exceto a partição hexânica, que inibiu em $21 \%$ a germinação do mata-pasto (Tabela 4).

Tabela 4 - Efeitos potenciais alelopáticos das partições do EBAE sobre a germinação das sementes das plantas daninhas

\begin{tabular}{|c|c|c|}
\hline \multirow{2}{*}{ Partição } & \multicolumn{2}{|c|}{ Espécie de planta daninha } \\
\cline { 2 - 3 } & Malícia & Mata-pasto \\
\hline PH & $100 \mathrm{Aa}$ & $21 \mathrm{Bb}$ \\
\hline PDM & $100 \mathrm{Aa}$ & $100 \mathrm{Aa}$ \\
\hline PAE & $100 \mathrm{Aa}$ & $100 \mathrm{Aa}$ \\
\hline
\end{tabular}

Médias seguidas de letras iguais, minúsculas na linha e maiúsculas na coluna, não diferem pelo teste de Tukey (5\%).

Dados expressos em percentual de inibição em relação ao tratamento testemunha (água destilada). Soluções utilizadas na concentração de $1 \%(\mathrm{~m} / \mathrm{v})$.

No desenvolvimento da radícula e do hipocótilo, as partições apresentaram significativa inibição desses parâmetros, principalmente na espécie malícia, com destaque para as partições hexânica e acetato de etila, que provocaram uma inibição, respectivamente, de 80,6 e $64,5 \%$, para a radícula, e 80,6 e $72,6 \%$, para o hipocótilo (Tabelas 5 e 6).

\section{Avaliação da atividade do potencial alelopático do óleo essencial}

Individualmente, as espécies receptoras apresentaram efeitos adversos à atividade potencialmente alelopática do óleo essencial na germinação das sementes. A malícia foi a espécie cuja germinação foi inibida em $71 \%$, enquanto o mata-pasto, especificamente, teve um efeito de estimulação de $60 \%$ na germinação de suas sementes (Figura 3). De acordo com An et al. (1993), uma dado efeito alelopático pode assumir dois atributos complementares, estimulatório e deletério. Complementando essa informação, Rice (1984) menciona que, quando em baixa concentração, os efeitos alelopáticos podem não ser inibitórios para determinadas espécies ou mesmo, até apresentar efeitos estimulatórios. Os resultados deste trabalho indicaram atributo inibitório para malícia e estimulatório para mata-pasto. Aparentemente, a concentração de $1 \%$ e as diferenças entre as duas espécies receptoras, em relação à atividade alelopática do óleo essencial, condicionaram as diferenças observadas.

Tabela 5 - Efeitos potenciais alelopáticos das partições do EBAE sobre o desenvolvimento da radícula das plantas daninhas

\begin{tabular}{|c|c|c|}
\hline \multirow{2}{*}{ Partição } & \multicolumn{2}{|c|}{ Espécie de planta daninha } \\
\cline { 2 - 3 } & Malícia & Mata-pasto \\
\hline PH & $80,6 \mathrm{Aa}$ & $0 \mathrm{Bb}$ \\
\hline PDM & $54,8 \mathrm{Ca}$ & $14 \mathrm{Ab}$ \\
\hline PAE & $64,5 \mathrm{Ba}$ & $14 \mathrm{Ab}$ \\
\hline
\end{tabular}

Médias seguidas de letras iguais, minúsculas na linha e maiúsculas na coluna, não diferem pelo teste de Tukey (5\%).

Dados expressos em percentual de inibição em relação ao tratamento testemunha (água destilada). Soluções utilizadas na concentração de $1 \%(\mathrm{~m} / \mathrm{v})$.

Tabela 6 - Efeitos potenciais alelopáticos das partições do EBAE sobre o desenvolvimento do hipocótilo das plantas daninhas

\begin{tabular}{|c|c|c|}
\hline \multirow{2}{*}{ Partição } & \multicolumn{2}{|c|}{ Espécie de planta daninha } \\
\cline { 2 - 3 } & Malícia & Mata-pasto \\
\hline PH & $80,6 \mathrm{Aa}$ & $25,0 \mathrm{Bb}$ \\
\hline PDM & $77,4 \mathrm{Ba}$ & $42,8 \mathrm{Ab}$ \\
\hline PAE & $72,6 \mathrm{Ca}$ & $12,5 \mathrm{Cb}$ \\
\hline
\end{tabular}

Médias seguidas de letras iguais, minúsculas na linha e maiúsculas na coluna, não diferem pelo teste de Tukey (5\%).

Dados expressos em percentual de inibição em relação ao tratamento testemunha (água destilada). Soluções utilizadas na concentração de $1 \%(\mathrm{~m} / \mathrm{v})$.

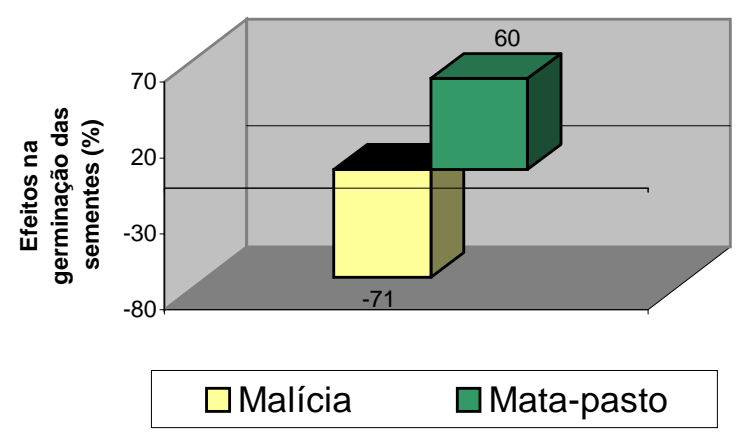

Dados expressos em percentual de efeito em relação ao tratamento testemunha (água destilada). Solução utilizada na concentração de 1 ppm.

Figura 3 - Efeito alelopático do óleo essencial na germinação das sementes das plantas daninhas. 
No desenvolvimento da radícula e do hipocótilo, os diferentes graus de sensibilidade aos efeitos potenciais alelopáticos do óleo essencial foram determinados pela concentração das soluções utilizadas, que teve em 20 ppm a maior inibição no desenvolvimento da radícula e do hipocótilo, que foi de 25 e $23 \%$, respectivamente, para a malícia, e de 35 e $21 \%$, respectivamente, para o mata-pasto (Tabelas 7 e 8 ).

Tabela 7 - Efeitos potenciais alelopáticos do óleo essencial das folhas de Myrcia guianensis sobre o desenvolvimento da radícula das plantas daninhas

\begin{tabular}{|c|c|c|}
\hline \multirow{2}{*}{$\begin{array}{c}\text { Concentração } \\
(\mathrm{ppm})\end{array}$} & \multicolumn{2}{|c|}{ Espécie de planta daninha } \\
\cline { 2 - 3 } & Malícia & Mata-pasto \\
\hline 5 & $6 \mathrm{Da}$ & $4 \mathrm{Da}$ \\
10 & $13 \mathrm{Ca}$ & $12 \mathrm{Ca}$ \\
\hline 15 & $20 \mathrm{Bb}$ & $26 \mathrm{Ba}$ \\
\hline 20 & $25 \mathrm{Ab}$ & $35 \mathrm{Aa}$ \\
\hline
\end{tabular}

Médias seguidas de letras iguais, minúsculas na linha e maiúsculas na coluna, não diferem pelo teste de Tukey (5\%).

Dados expressos em percentual de inibição em relação ao tratamento testemunha (água destilada).

Tabela 8 - Efeitos potenciais alelopáticos do óleo essencial das folhas de Myrcia guianensis sobre o desenvolvimento do hipocótilo das plantas daninhas

\begin{tabular}{|c|c|c|}
\hline \multirow{2}{*}{$\begin{array}{c}\text { Concentração } \\
(\mathrm{ppm})\end{array}$} & \multicolumn{2}{|c|}{ Espécie de planta daninha } \\
\cline { 2 - 3 } & Malícia & Mata-pasto \\
\hline 5 & $4 \mathrm{Da}$ & $6 \mathrm{Ca}$ \\
\hline 10 & $12 \mathrm{Ca}$ & $7 \mathrm{Cb}$ \\
\hline 15 & $17 \mathrm{Ba}$ & $10 \mathrm{Bb}$ \\
\hline 20 & $23 \mathrm{Aa}$ & $21 \mathrm{Aa}$ \\
\hline
\end{tabular}

Médias seguidas de letras iguais, minúsculas na linha e maiúsculas na coluna, não diferem pelo teste de Tukey (5\%).

Dados expressos em percentual de inibição em relação ao tratamento testemunha (água destilada).

Os óleos essenciais são considerados como potentes inibidores da germinação de sementes e do crescimento de diversas plantas, tanto na forma original, em mistura, quanto de seus constituintes isoladamente (Kohli \& Singh, 1991; Souto et al., 1995; Duke et al., 2000). No presente trabalho, a intensidade dos efeitos sobre a germinação da sementes da espécie malícia foi expressiva (71\% de inibição). Já as inibições efetivadas sobre o desenvolvimento da radícula e do hipocótilo, foram de menor magnitude, não ultrapassaram os 35\%. Aparentemente, o óleo essencial da $M$. guianensis apresenta maior potencial como agente inibidor da germinação de sementes do que do desenvolvimento da radícula e do hipocótilo das plantas daninhas.

\section{Avaliação da atividade do potencial alelopático das substâncias químicas}

A atividade alelopática inibitória dos ácidos protocatecuico (Tabelas 9-11) e gálico (Tabelas 12-14) esteve associado a dois fatores: concentração e planta receptora. A tendência geral observado foi de relação positiva entre intensidade de inibição e a concentração do ácido, com efeitos máximos obtidos na concentração de 60 ppm, embora diferenças estatísticas, em muitos casos, não tenham sido observados.

Tabela 9 - Efeitos potenciais alelopáticos do ácido protocatecuico na germinação das sementes das plantas daninhas

\begin{tabular}{|c|c|c|}
\hline \multirow{2}{*}{$\begin{array}{c}\text { Concentração } \\
(\mathrm{ppm})\end{array}$} & \multicolumn{2}{|c|}{ Espécie de planta daninha } \\
\cline { 2 - 3 } & Malícia & Mata-pasto \\
\hline 15 & $0 \mathrm{Ca}$ & $0 \mathrm{Ba}$ \\
\hline 30 & $0 \mathrm{Ca}$ & $0 \mathrm{Ba}$ \\
\hline 45 & $5 \mathrm{Bb}$ & $10 \mathrm{Aa}$ \\
\hline 60 & $10 \mathrm{Aa}$ & $11 \mathrm{Aa}$ \\
\hline
\end{tabular}

Médias seguidas de letras iguais, minúsculas na linha e maiúsculas na coluna, não diferem pelo teste de Tukey (5\%).

Dados expressos em percentual de inibição em relação ao tratamento testemunha (água destilada).

Tabela 10 - Efeitos potenciais alelopáticos do ácido protocatecuico no desenvolvimento da radícula das plantas daninhas

\begin{tabular}{|c|c|c|}
\hline \multirow{2}{*}{$\begin{array}{c}\text { Concentração } \\
(\mathrm{ppm})\end{array}$} & \multicolumn{2}{|c|}{ Espécie de planta daninha } \\
\cline { 2 - 3 } & Malícia & Mata-pasto \\
\hline 15 & $3 \mathrm{Ca}$ & $0 \mathrm{Cb}$ \\
\hline 30 & $6 \mathrm{Ba}$ & $2 \mathrm{Cb}$ \\
\hline 45 & $8 \mathrm{Ba}$ & $9 \mathrm{Ba}$ \\
\hline 60 & $14 \mathrm{Aa}$ & $16 \mathrm{Aa}$ \\
\hline
\end{tabular}

Médias seguidas de letras iguais, minúsculas na linha e maiúsculas na coluna, não diferem pelo teste de Tukey (5\%).

Dados expressos em percentual de inibição em relação ao tratamento testemunha (água destilada). 
Semelhantemente, a espécie malícia tendeu a ser mais sensivel aos efeitos dos dois ácidos do que mata-pasto, conquanto diferenças estatística não tenham sido detectadas em diversas comparações.

Tabela 11 - Efeitos potenciais alelopáticos do ácido protocatecuico no desenvolvimento do hipocótilo das plantas daninhas

\begin{tabular}{|c|c|c|}
\hline \multirow{2}{*}{$\begin{array}{c}\text { Concentração } \\
(\mathrm{ppm})\end{array}$} & \multicolumn{2}{|c|}{ Espécie de planta daninha } \\
\cline { 2 - 3 } & Malícia & Mata-pasto \\
\hline 15 & $4 \mathrm{Ca}$ & $0 \mathrm{Db}$ \\
\hline 30 & $8 \mathrm{Ba}$ & $5 \mathrm{Cb}$ \\
\hline 45 & $9 \mathrm{Ba}$ & $9 \mathrm{Ba}$ \\
\hline 60 & $15 \mathrm{Aa}$ & $13 \mathrm{Aa}$ \\
\hline
\end{tabular}

Médias seguidas de letras iguais, minúsculas na linha e maiúsculas na coluna, não diferem pelo teste de Tukey $(5 \%)$.

Dados expressos em percentual de inibição em relação ao tratamento testemunha (água destilada).

Tabela 12 - Efeitos potenciais alelopáticos do ácido gálico na germinação das sementes das plantas daninhas

\begin{tabular}{|c|c|c|}
\hline \multirow{2}{*}{$\begin{array}{c}\text { Concentração } \\
(\mathrm{ppm})\end{array}$} & \multicolumn{2}{|c|}{ Espécie de planta daninha } \\
\cline { 2 - 3 } & Malícia & Mata-pasto \\
\hline 15 & $0 \mathrm{Ca}$ & $0 \mathrm{Ba}$ \\
\hline 30 & $0 \mathrm{Ca}$ & $0 \mathrm{Ba}$ \\
\hline 45 & $3 \mathrm{Ba}$ & $3 \mathrm{Aa}$ \\
\hline 60 & $6 \mathrm{Aa}$ & $5 \mathrm{Aa}$ \\
\hline
\end{tabular}

Médias seguidas de letras iguais, minúsculas na linha e maiúsculas na coluna, não diferem pelo teste de Tukey $(5 \%)$.

Dados expressos em percentual de inibição em relação ao tratamento testemunha (água destilada).

Tabela 13 - Efeitos potenciais alelopáticos do ácido gálico no desenvolvimento da radícula das plantas daninhas

\begin{tabular}{|c|c|c|}
\hline \multirow{2}{*}{$\begin{array}{c}\text { Concentração } \\
(\mathrm{ppm})\end{array}$} & \multicolumn{2}{|c|}{ Espécie de planta daninha } \\
\cline { 2 - 3 } & Malícia & Mata-pasto \\
\hline 15 & $3 \mathrm{Ca}$ & $0 \mathrm{Db}$ \\
\hline 30 & $5 \mathrm{Ca}$ & $4 \mathrm{Ca}$ \\
\hline 45 & $8 \mathrm{Ba}$ & $10 \mathrm{Ba}$ \\
\hline 60 & $11 \mathrm{Ab}$ & $14 \mathrm{Aa}$ \\
\hline
\end{tabular}

Médias seguidas de letras iguais, minúsculas na linha e maiúsculas na coluna, não diferem pelo teste de Tukey $(5 \%)$.

Dados expressos em percentual de inibição em relação ao tratamento testemunha (água destilada).
Tabela 14 - Efeitos potenciais alelopáticos do ácido gálico no desenvolvimento do hipocótilo das plantas daninhas

\begin{tabular}{|c|c|c|}
\hline $\begin{array}{c}\text { Concentração } \\
(\mathrm{ppm})\end{array}$ & \multicolumn{2}{|c|}{ Espécie de planta daninha } \\
\cline { 2 - 3 } & Malícia & Mata-pasto \\
\hline 15 & $0 \mathrm{Ca}$ & $0 \mathrm{Ca}$ \\
\hline 30 & $3 \mathrm{Ba}$ & $2 \mathrm{Ca}$ \\
\hline 45 & $4 \mathrm{Ba}$ & $5 \mathrm{Ba}$ \\
\hline 60 & $8 \mathrm{Aa}$ & $8 \mathrm{Aa}$ \\
\hline
\end{tabular}

Médias seguidas de letras iguais, minúsculas na linha e maiúsculas na coluna, não diferem pelo teste de Tukey $(5 \%)$.

Dados expressos em percentual de inibição em relação ao tratamento testemunha (água destilada).

Atividade alelopática relacionada aos ácidos gálico e protocatecuico, à semelhança do presente trabalho, são encontrados nos artigos de Ramamoorthy \& Paliwal (1993) e Kill \& Yang-Jai (1993). Entretanto, as intensidades das inibições foram extremamente baixas quando se considera os efeitos obtidos para outras substâncias, em concentrações similares, como são os casos do ácido p-cumárico (Souza Filho et al., 2005b) e do 4,5-diidroblumenol A (Souza Filho et al., 2005a). Aparentemente, concentração e especificidade entre substâncias e plantas receptoras são fatores que contribuiram para os resultados alcançados. Por outro lado, o fato dos extratos brutos (Tabela 3) e partições (Tabelas 4 e 5) terem produzido altas taxas de inibições, sugerem que outras substâncias, não isoladas neste trabalho, estejam relacionadas nas atividade alelopática de $M$. guianensis.

\section{LITERATURA CITADA}

AN, M.; JOHNSON, I.R.; LOVETTE, J. V. Mathematical modelling of allelopathy: biological response to allelochemicals and its interpretation. J. Chem. Ecol., v. 19, p. 2379-2389, 1993.

ANDERSEN, O. M. et al. Anthocyanins acylated with galic acid from chenile plant, Acalypha hispida. Phytochemistry, v. 64 , p. 867-871, 2003.

BORGES, E. E. L.; LOPES, E. S.; SILVA, G. F. Avaliação de substâncias alelopáticas em vegetação de uma floresta secundária. 1- árvore. R. Árvore, v. 17, n. 1, p. 69-84, 1993. 
DUKE, S.O.; ROMAGNI, J.G.; DAYAN, F.E. Natural products as sources from new mechanisms of herbicidal action. Crop Products, v.19, p.583-589, 2000.

GONZÁLES, L.; SOUTO, X. C.; REIGOSA, M. J. Allelopathic effects of Acacia melanoxylon R. Br. Phyllodes during their decomposition. For. Ecol. Manag., v. 77, n. 1-3, p. 53-63, 1995.

GUARÉ CRUZ, F. et al. Seasonal composition and antimicrobial activity of essential oils from Myrcia multiflora DC. (Myrtaceae). Disponível em: <www.pharma.unime.it/ foodchem/iseo2004/p.92.pdf>. Acesso em: 10 jan. 2006.

KILL, B. S.; YANG-JAI, T. Allelopathic effects of Pinus densiflora on undergrowth of red pine forest. J. Chem. Ecol., v. 9, n. 8, p. 1135-1151, 1993.

KOHLI, R. K.; SINGH, D. Allelopathic impact of volatile compounds from Eucalyptus on crop plants. Biol. Plant., v. 33, p. 475-483, 1991.

LIMBERGER, R. P.; SOBRAL, M.; HENRIQUES, A. T. Óleos voláteis de espécies de Myrcia nativas do Rio Grande do Sul. Quim. Nova, v. 27, n. 6, p. 916-919, 2004.

LISANEWORK, N.; MICHELSEN, A. Allelopathy in agroforestry systems: the effects of leaf extracts of Cupressus lusitania and Eucaliptus spp. on four ethiopian crops. Agrofor. Syst., v. 21, n. 1, p. 63-74, 1993.

MATSUDA, H.; MORIKAWA, T.; YOSHIKAWA, M. Antidiabetogenic constituents from several natural medicines. Pure Appl. Chem., v. 74, n. 7, p. 1301-1308, 2002.

MATSUDA, $\mathrm{H}$. et al. Aldose redutase and new triterpene and Its oligoglycoside, centellasapogenol A and centellasaponina, from Centela asiatica (gotu kola). Heterocycles, v. 55, p. 1499-1504, 2001.

NUNEZ SELLES, A. et al. Isolation and quantitative analysis of phenolic antioxidants, free sugar, and, polyols from Mango (Mangifera indica L.) Sten Bark Aqueous Decoccion Used in Cuba as a nutritional suplement. J. Agric. Food Chem., v. 50, p. 762-766, 2002.
RAMAMOORTHY, M.; PALIWAL, K. Allelopathic compounds in leaves of Gliricidia sepium (Jacq.) Kunth ex Walp. and its effects. J. Chem. Ecol., v. 19, n. 8, p. 16911701, 1993.

RICE, E. L. Allelopathy. New York: Academic Press, 1984. $422 \mathrm{p}$.

RIZVI, D. J. H. et al. Allelopathy interation in agroforestry systems. Crit. Rev. Plant Sci., v. 18, n. 6, p. 773-796, 1999.

SOUTO, X. C.; GONZÁLES, L.; REIGOSA, M. J. Allelopathy in forest environmental in Galícia, Spain. Allelopathy Journal, v. 2, p. 67-78, 1995.

SOUZA FILHO, A. P. S.; ALVES, S. M. Potencial alelopatico de plantas de acapu (Vouacapoua americana): efeitos sobre plantas daninhas de pastagens. Planta Daninha, v. 18, n. 3, p. 435-441, 2000.

SOUZA FILHO, A. P. S.; LÔBO, L. T.; ARRUDA, M. S. P. Atividade alelopática de folhas de Tachigali myrmecophyla (Leg.- Pap.). Planta Daninha, v. 23, n. 4, p. 557-564, 2005a.

SOUZA FILHO, A. P. S.; PEREIRA, A. A. G.; BAYMA, J. C. Aleloquímico produzido pela gramínea forrageira Brachiaria humidicola. Planta Daninha, v. 23, n. 1, p. 25-32, 2005 b.

SOUZA FILHO, A. P. S.; PEREIRA, A. A. G.; BAYMA, J. C. Aleloquímico produzido pela gramínea forrageira Brachiaria humidicola. Planta Daninha, v. 23, n. 1, p. 25-32, 2005.

STATISTICAL ANALYSIS SYSTEM - SAS. User's guide. Version 6.4. Cary: 1989. $846 \mathrm{p}$.

YOSHIKAWA, M.; MATSUDA, H.; NISHIDA, N. Antidiabetic principles of natural medicines. V.1) Aldose Reductase Inhibitors from Myrcia multiflora DC. (2): Structures of Myrciacitrins III, IV, and V. Chem. Pharm. Bull., v. 50, n. 3, p. 429-431, 2002.

YOSHIKAWA, M. et al. Antidiabetic principles of natural medicines. II: aldore redutase and D-glucosidase inhibitors from brazilian natural medicines, The leaves of Myrcia multiflora DC. (Myrtaceae): Struture of myrciacitrins I and II and myrciphenones A and B. Chem. Pharm. Bull., v. 46, n. 1, p. 113-119, 1998. 